\title{
Pilot Method for Propagating an Assortment of Medicinal Plants Using Water Retaining Starch Polymers
}

\author{
Valentin SINGUREANU ${ }^{1 *}$, Gelu MOLDOVAN ${ }^{1)}$, Rodica UNGUR ${ }^{2)}$, Ioan ONAC ${ }^{2)}$, Victoria SINGUREANU ${ }^{3)}$ \\ 1) University of Agricultural Sciences and Veterinary Medicine Cluj-Napoca, Manastur Street, No. 3-7, \\ Romania. \\ 2) Iuliu Haţieganu University of Medicine and Pharmacy Cluj-Napoca, Babeş Street, No. 8, Romania. \\ ${ }^{3)}$ Rehabilitation Clinical Hospital Cluj-Napoca, Viilor Street, No. 46-50, Romania. \\ ${ }^{*}$ Corresponding authors, e-mails: singvalentin@yahoo.com
}

Bulletin UASVM Horticulture 71(2) / 2014

Print ISSN 1843-5254, Electronic ISSN 1843-5394

DOI:10.15835/buasvmcn-hort:10729

\begin{abstract}
The research illustrates use of starch polymeric substrate for vegetative propagation of medicinal plants vs. perlite substrate. The experimental plot was emplaced in a standard greenhouse located in Cluj-Napoca, during approximately two months (12.12.2013-03.02.2014). The biological material integrated key members of the Lamiaceae family: Salvia officinalis, Mentha piperita, and Rosmarinus officinalis. Microclimatic conditions where observed on decades: light intensity (lux), environmental temperature $\left({ }^{\circ} \mathrm{C}\right)$, substrate temperature $\left({ }^{\circ} \mathrm{C}\right)$ and relative humidity (\%). The rooting percent, number of secondary and primary roots, was evaluated using specific 3D software, which generated exact 3D models from pictures. Rooting percent is higher for unshaded perlite substratum at Rosmarinus officinalis (84\%). Salvia officinalis reacted different at rooting substratum assuring better radication percents for the shaded perlite substratum (61\%) suggesting that the leaf area for this species is better conserved for evapotranspiration at the shaded experimental variants. Mentha piperita recorded the same rooting percent for the perlite substratum $(17 \%)$ regardless the shading method. Radication percent for the water retaining starch polymers was null for Mentha piperita and Rosmarinus officinalis. Overall all the experimental material propagated in water retaining starch polymers suffered by water excess and reduced oxygen permeability. Correlations where made using Pearson index $(\mathrm{r})$ regarding the height of cuttings and number of secondary roots. In general, taller cuttings assured increased number of secondary roots.
\end{abstract}

Keywords: medicinal plants, 3D, cutting, medicinal, rooting percent

\section{INTRODUCTION}

During the past years, market demand for medicinal herbs has increased sharply involving trades between European and non-european countries. Statistics speak for themselves, now $25 \%$ of modern pharmaceutical drugs contain chemical ingredients extracted from plants (Harknes et al., 2000) (Thomas, 2004). Economical calculations based on U.N. Comtrade statistics show that exported value in thousand US dollars of medicinal plants in the world was 3399349 (2013), 2662341 (2012) with a positive difference of 737008 thousand dollars (http://www.intracen.org). In Romania, the export income generated by medicinal plant is rising with an amount of 3014 thousand dollars in 2013 (Thomas, 2004). Considering the international trade statistic database and the importance of medicinal plants in the world, the paper illustrates new methods for cuttings propagation and their behavior to greenhouse environmental conditions. Antioxidant and antimicrobial medical importance for the Lamiaceae conducted to experimental factor integration of Salvia officinalis, Mentha piperita, and Rosmarinus officinalis (D'Antuono et al., 2006).

Cutting propagation is the optimum solution despite the sowing technique, due to its genotypic conservation (Fornes et al., 2013). Micro cuttings are excluded from the experiment for economic reasons and chemical changes at flavors and antioxidant capacity (Nimet and Hasan, 2013), (Pistelli et al., 2013). 


\section{MATERIALS AND METHODS}

The experimental plot was emplaced in a standard greenhouse located in Cluj-Napoca, Romania. The experimental plot duration spread between 12.12.2013-03.02.2014.

The experiment is a 3 factor randomized plot with 4 repetition as follows (Fig. 1).

Each experimental variant consisted in 18 edge cuttings. All the cuttings where prevailed from the Botanical Garden of USAMV Cluj-Napoca. For the perlite substratum, we used granular perlite with a medium diameter of 1,5-3 $\mathrm{mm}$. The water retaining starch polymers has represented by $15 \mathrm{~g}$ of brut material that cumulated $7000 \mathrm{ml}$ of water (fig. 2).

The shading material is represented by a standard green plastic woven material with a light reflection capacity of $35 \%$. During the experiment, environmental factors where observed in dynamic with a digital multimeter that recorded light intensity (lux), environmental temperature $\left({ }^{\circ} \mathrm{C}\right)$, substrate temperature $\left({ }^{\circ} \mathrm{C}\right)$ and relative humidity (\%). At the end of the experiment cuttings, where photographed and imported in specific 3D software that helped the research team to investigate level of development generating an accurate 3D model of the cutting with a specific color diffusion map (Joosen et al., 2009). Considering that a welldeveloped cutting has numerous secondary roots, correlations where made using Pearson index (r) regarding the height of cuttings and number of secondary roots (Andrade et al., 1999).

\section{RESULTS AND DISCUSSION}

Environmental conditions inside the greenhouse where divided by category: relative humidity (\%), environmental temperature $\left({ }^{\circ} \mathrm{C}\right)$, substrate temperature $\left({ }^{\circ} \mathrm{C}\right)$ and light intensity (lux), observed on decades. During one decade all the experimental factors presented above were recorded at $9 \mathrm{AM}$ and $14 \mathrm{PM}$.

The relative air humidity recorded the highest value at 9 PM in 10.01.2014 (83.40\%). Similar values of outside relative air humidity react synergic to relative air humidity inside the greenhouse. Overall the relative air humidity was constant as average during the experimental procedure with average values of $59.70 \%$ at 9 $\mathrm{AM}$ and 59.80 at 14 PM (Fig. 3). Therefore, we concluded that environmental conditions are in standard parameters.

At 9 AM temperature of the greenhouse influenced substratum temperatures in the following order: shaded perlite substrate recorded the lowest temperature $\left(10.90{ }^{\circ} \mathrm{C}\right)$, followed by shaded water retaining starch polymers $(11.30$ $\left.{ }^{\circ} \mathrm{C}\right)$. Minimum temperatures are observed in 02.06.2014, date considered to be, with the lowest environmental temperatures recorded in the greenhouse $\left(13.97{ }^{\circ} \mathrm{C}\right)$ (Fig. 4).

As it can be seen in figure 4 environmental temperature influenced substratum temperature. Lower values for substratum temperature where observed in shaded experimental variants where light intensity was reduced proportional to caloric

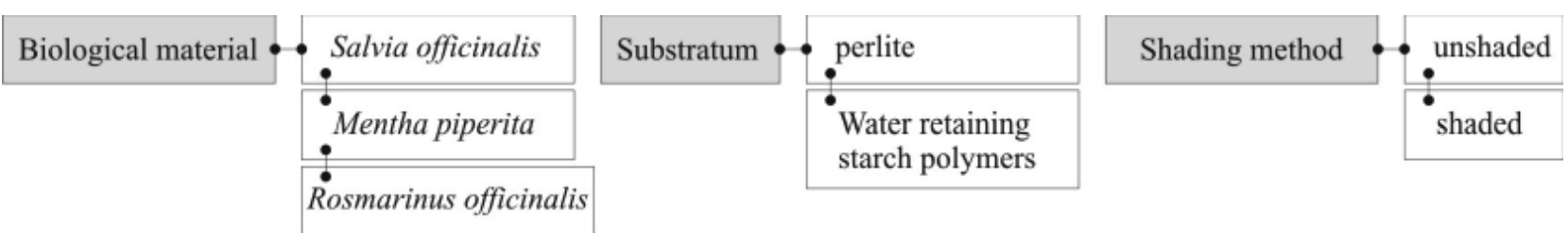

Fig. 1. Experimental factors graduation (original)
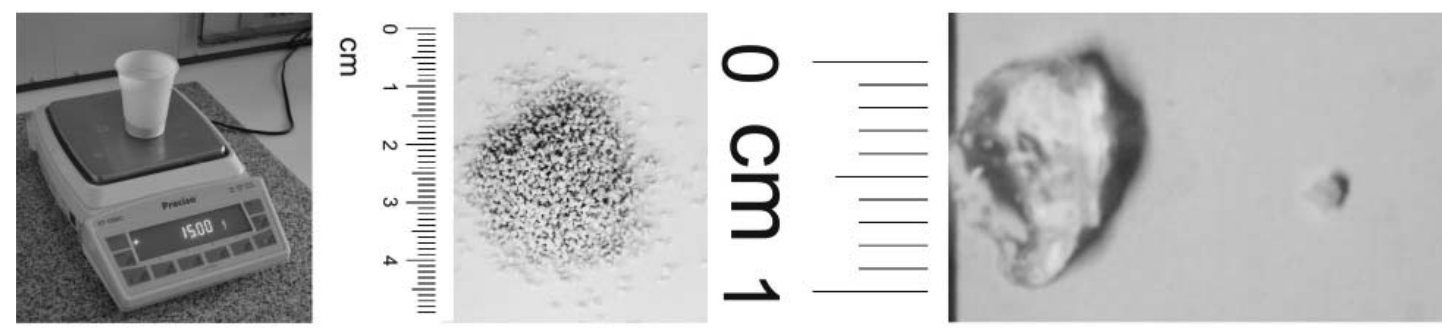

Fig. 2. Water retaining properties of the starch polymer (original) 

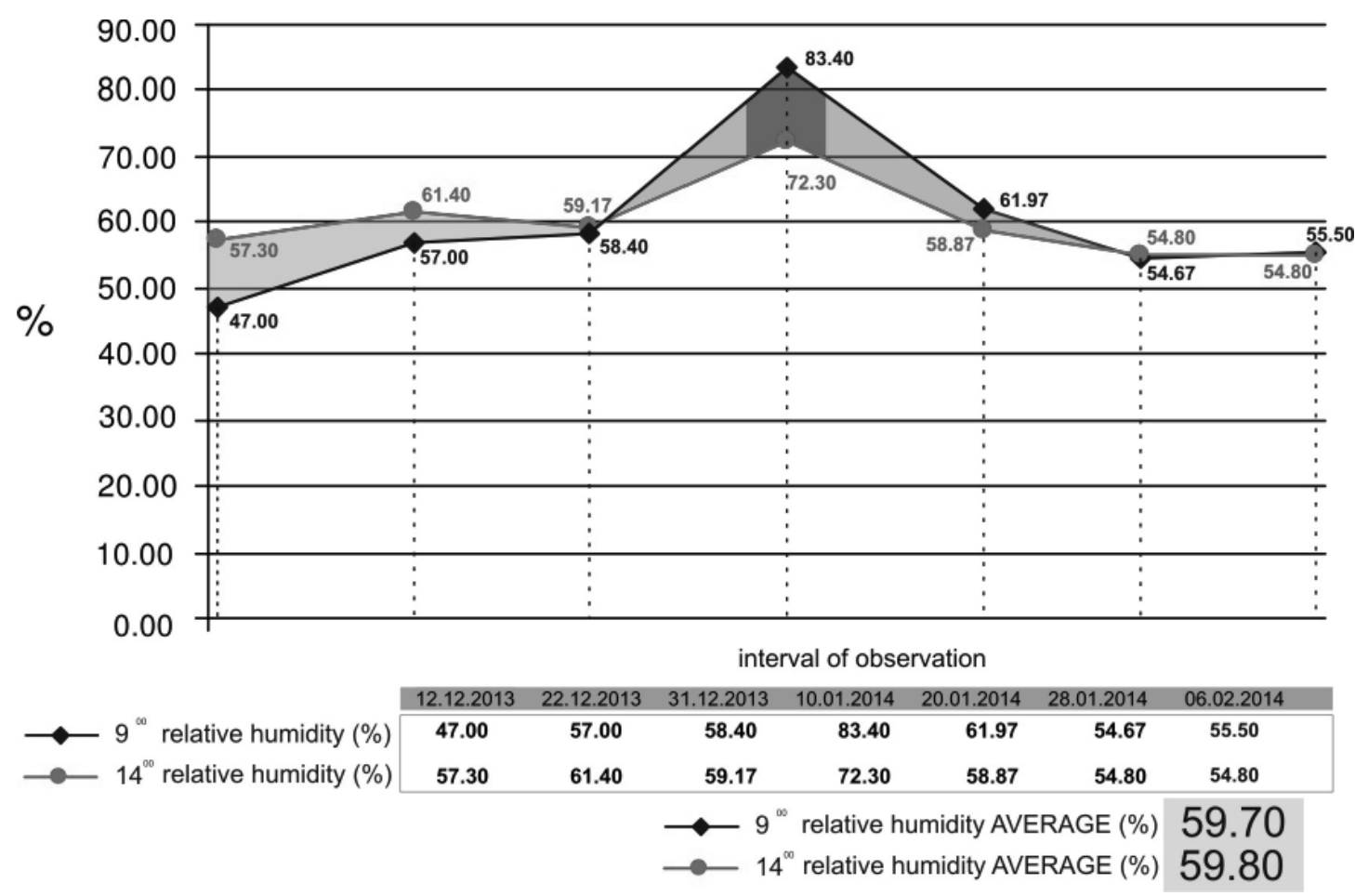

Fig. 3 Relative air humidity (\%) during the experimental plot at 9 AM and 14 PM (original)

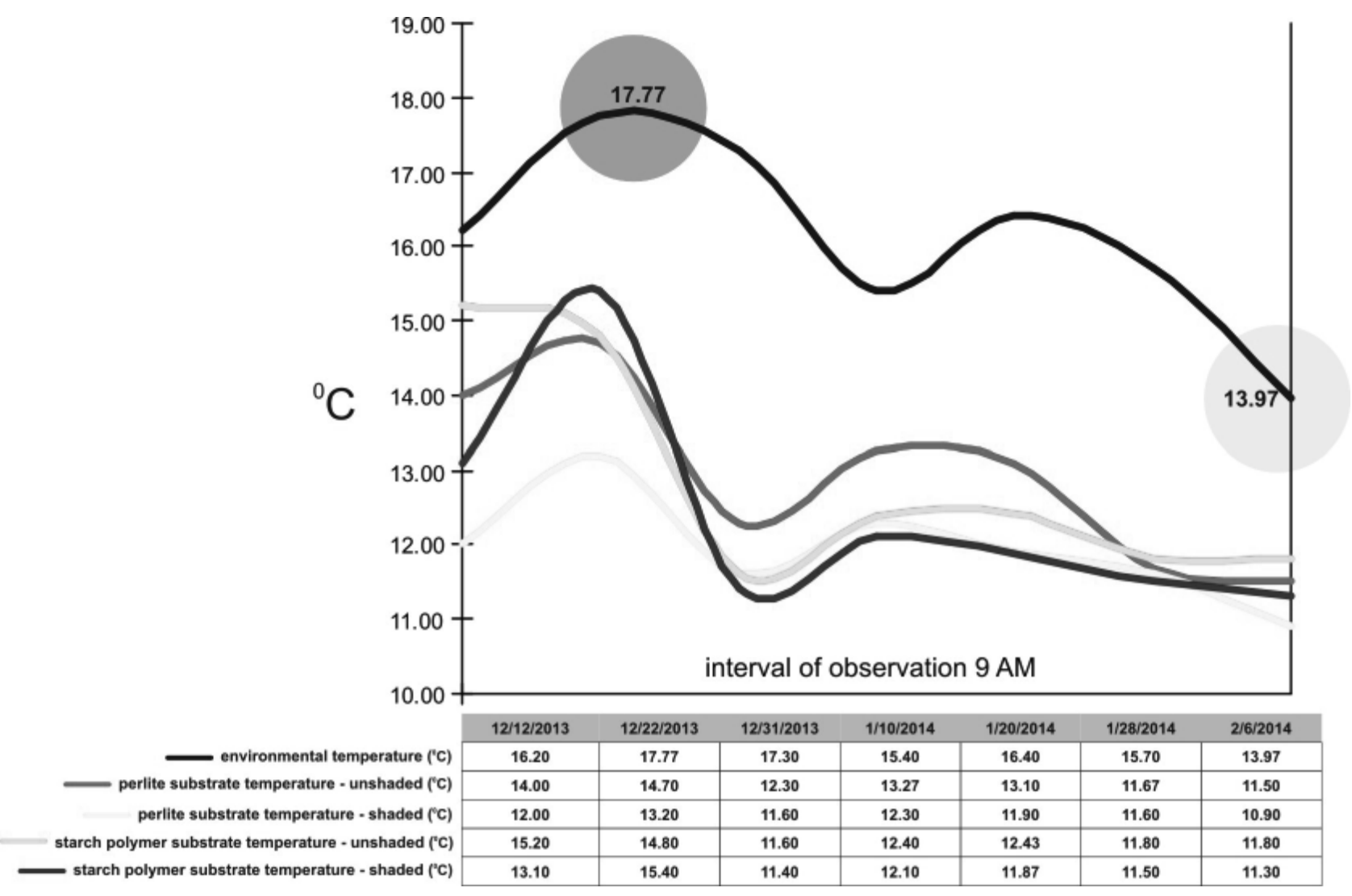

Fig. 4 Temperature correlation between environment and substratum at 9AM (original) 
input. All the temperature diagrams have the same trade suggesting a direct and positive correlation between environmental temperature and subtrate temperature.

Identical temperature correlation was observed for the 14 PM readings, where the same date and the same substrates recorded the lowest values as follows: shaded perlite substrate recorded the $\left(13.03{ }^{\circ} \mathrm{C}\right)$, followed by shaded water retaining starch polymers $\left(13.57^{\circ} \mathrm{C}\right)$ (Fig. 5).
Light intensity recorded in dynamic, as general environmental factor and intensity under the shading material is present in figure 6 . The main goal of the shading material was to reduce the water stress for the cuttings assuring optimum evapotranspiration. Figure 6 illustrate the light intensity reduction factor for the shaded experimental variants at 9 AM (Fig. 6 - a) and 14 PM (Fig. 6 - b).

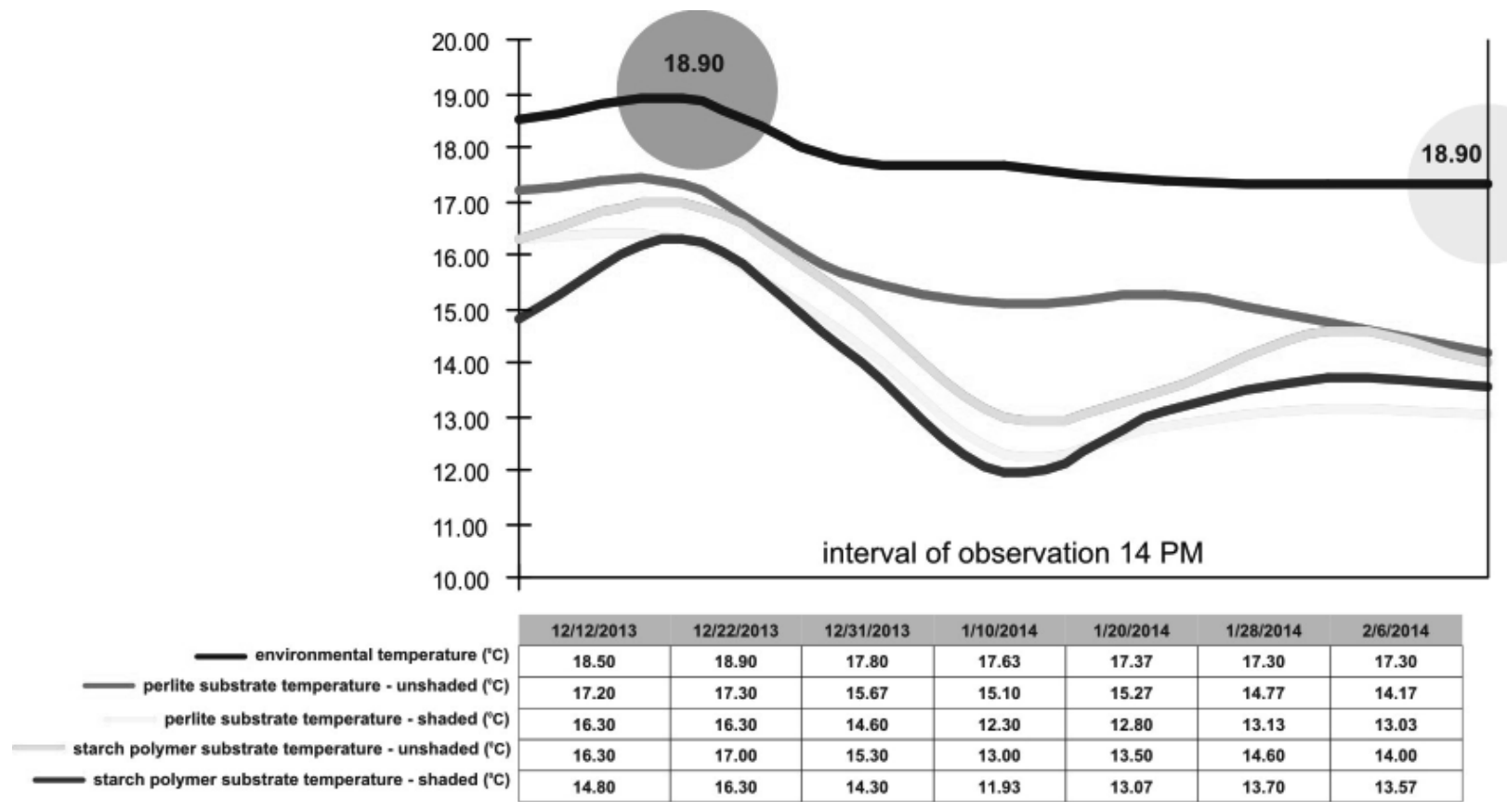

Fig. 5. Temperature correlation between environment and substratum at 14 PM (original)
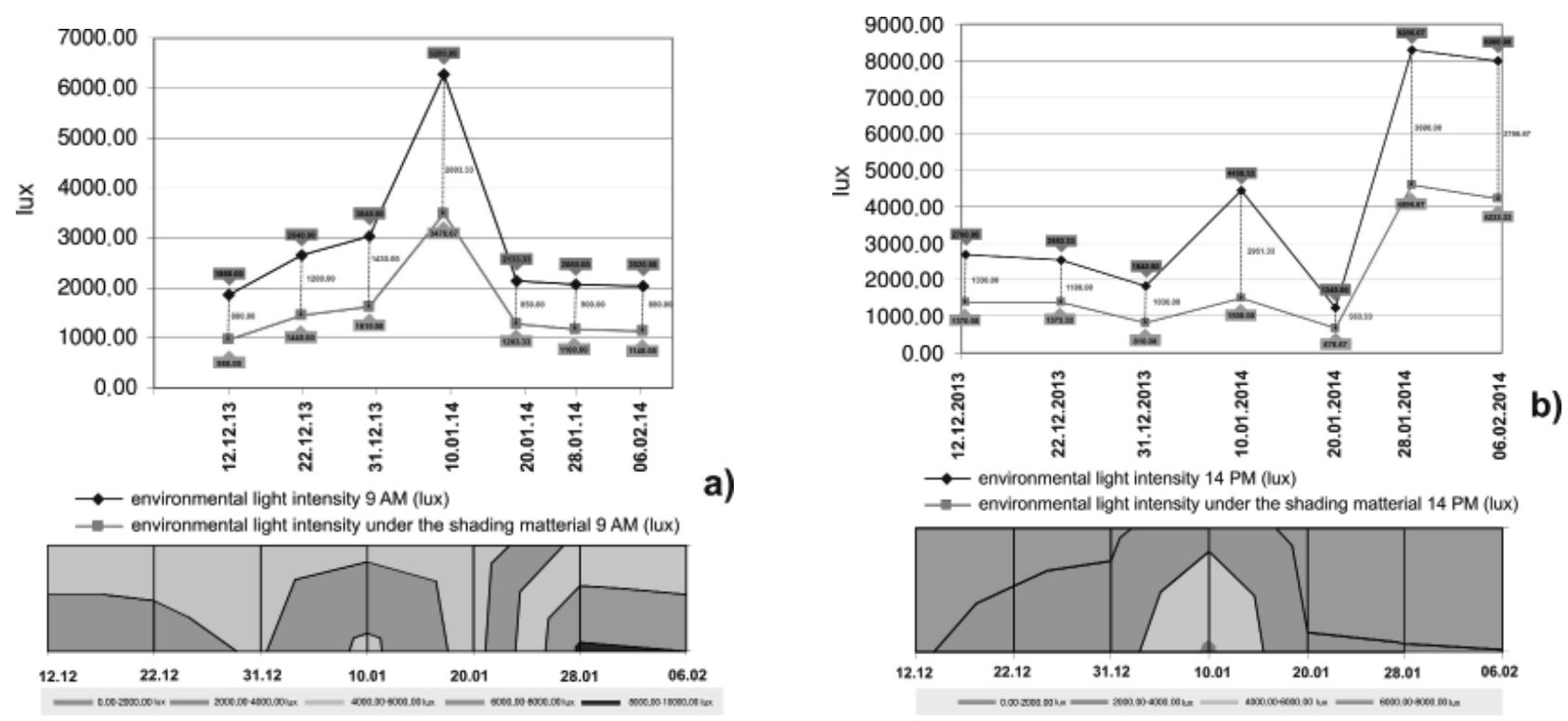

Fig. 6. a) Light intensity recordings at $9 \mathrm{AM}$; b) Light intensity recordings at $14 \mathrm{PM}$ 
Tab. 1. Rooting percent and Pearson index (r) for the experimental variants (original)

\begin{tabular}{|c|c|c|c|c|c|c|c|}
\hline \multicolumn{8}{|c|}{ Biological material } \\
\hline \multicolumn{8}{|c|}{ Rosmarinus officinalis } \\
\hline \multicolumn{4}{|c|}{ Substrate 1 - Perlite } & \multicolumn{4}{|c|}{ Substrate 2 - water retaining starch polymers } \\
\hline \multicolumn{2}{|c|}{ shaded } & \multicolumn{2}{|c|}{ un-shaded } & \multicolumn{2}{|c|}{ shaded } & \multicolumn{2}{|c|}{ un-shaded } \\
\hline rooting $\%$ & $\mathrm{r}$ & rooting $\%$ & $\mathrm{r}$ & rooting $\%$ & $\mathrm{r}$ & rooting $\%$ & $\mathrm{r}$ \\
\hline $50 \%$ & $(\mathrm{r}=0,58)$ & $84 \%$ & $(r=0,81)$ & $17 \%$ & $(r=-0,85)$ & $0 \%$ & $(\mathrm{r}=0)$ \\
\hline \multicolumn{8}{|c|}{ Salvia officinalis } \\
\hline \multicolumn{4}{|c|}{ Substrate 1 - Perlite } & \multicolumn{4}{|c|}{ Substrate 2 - water retaining starch polymers } \\
\hline \multicolumn{2}{|c|}{ shaded } & \multicolumn{2}{|c|}{ un-shaded } & \multicolumn{2}{|c|}{ shaded } & \multicolumn{2}{|c|}{ un-shaded } \\
\hline rooting \% & $\mathrm{r}$ & rooting $\%$ & $\mathrm{r}$ & rooting $\%$ & $\mathrm{r}$ & rooting $\%$ & $\mathrm{r}$ \\
\hline $61 \%$ & $(\mathrm{r}=0,52)$ & $56 \%$ & $(\mathrm{r}=0,83)$ & $39 \%$ & $(\mathrm{r}=0,60)$ & $28 \%$ & $(\mathrm{r}=0,24)$ \\
\hline \multicolumn{8}{|c|}{ Mentha piperita } \\
\hline \multicolumn{4}{|c|}{ Substrate 1 - Perlite } & \multicolumn{4}{|c|}{ Substrate 2 - water retaining starch polymers } \\
\hline \multicolumn{2}{|c|}{ shaded } & \multicolumn{2}{|c|}{ un-shaded } & \multicolumn{2}{|c|}{ shaded } & \multicolumn{2}{|c|}{ un-shaded } \\
\hline rooting $\%$ & $\mathrm{r}$ & rooting $\%$ & $\mathrm{r}$ & \multicolumn{2}{|c|}{ rooting $\%$} & \multicolumn{2}{|c|}{$\mathrm{r}$} \\
\hline \multicolumn{2}{|c|}{$17 \%(r=0,90)$} & \multicolumn{2}{|c|}{$17 \%(r=0,70)$} & \multicolumn{2}{|c|}{$0 \%(r=0)$} & \multicolumn{2}{|c|}{$0 \%(\mathrm{r}=0)$} \\
\hline
\end{tabular}

The shading material reacted as expected to environmental conditions reducing the light intensity with an average of $30 \%$ as shown by manufacturer. At 9 AM (Fig. 6 - a) the light intensity spreading chart reports that most of the light intensity is situated between 2000-4000 lux. In dynamic the light intensity for $14 \mathrm{PM}$ is situated between 4000-8000 lux (Fig. 6 - b) enough for an optimum rooting percent (Buschermohle, et al., 2004) (Lange, 2004).

Disruption of the experimental plot in 06.02.2014 revealed final rooting percent and correlation based on Pearson index between height of the cutting and its secondary roots (Tab. 1).

Rosmarinus officinalis experimental variants propagated on un-shaded perlite substrate recorded the highest rooting percent $84 \%$ with a Pearson index of 0.81 between height of cutting and secondary roots (Fig. 7). The value of the Pearson index in this case statistically assures a direct and positive correlation between the height of the cuttings and their number of secondary roots.

The correlation between height of the cutting and secondary roots establish qualitative standards for well-developed nursery material.

Rosmarinus officinalis cuttings propagated on un-shaded or shaded perlite substratum develop young plants situated at the collar. This aspect creates general premises for recommending perlite substratum propagation in this case (Fig. 8).

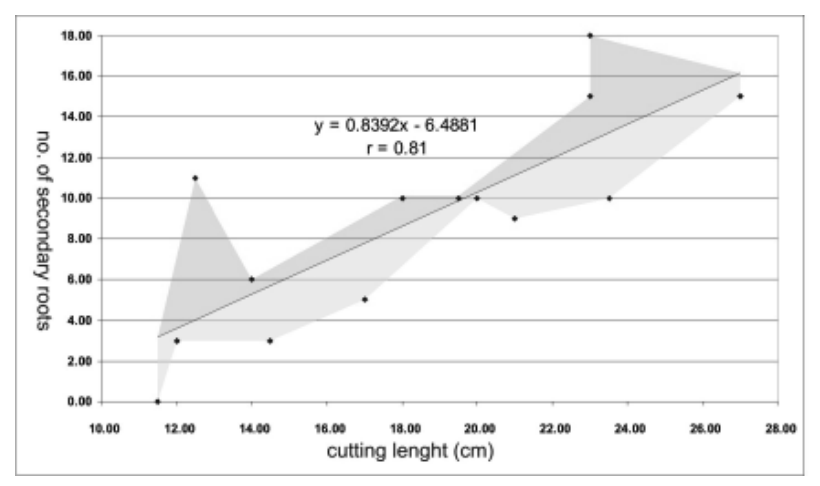

Fig. 7. Correlation coefficient between cutting length and number of secondary roots at Rosmarinus officinalis propagated on un-shaded perlite (original)

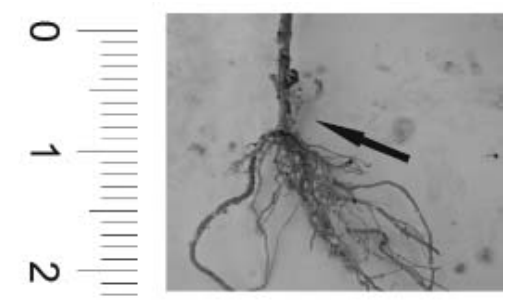

Fig. 8. Young plant development at the Rosmarinus officinalis collar 

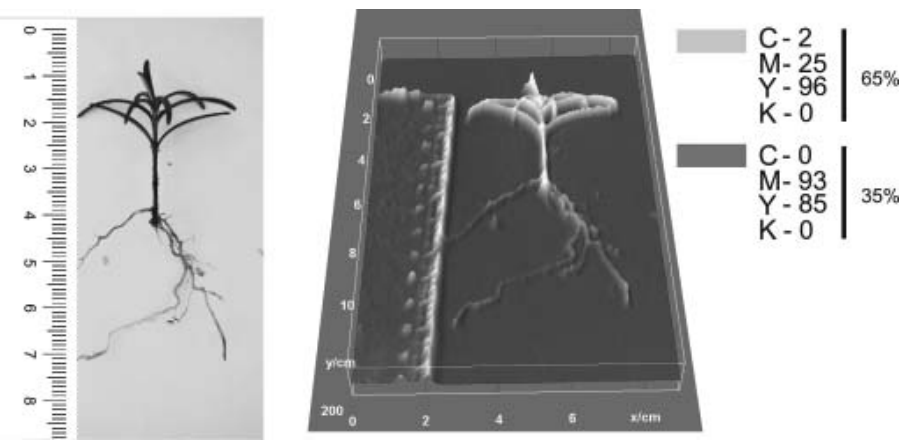

Fig. 9. Cutting development at Rosmarinus officialis propagated on un-shaded perlite
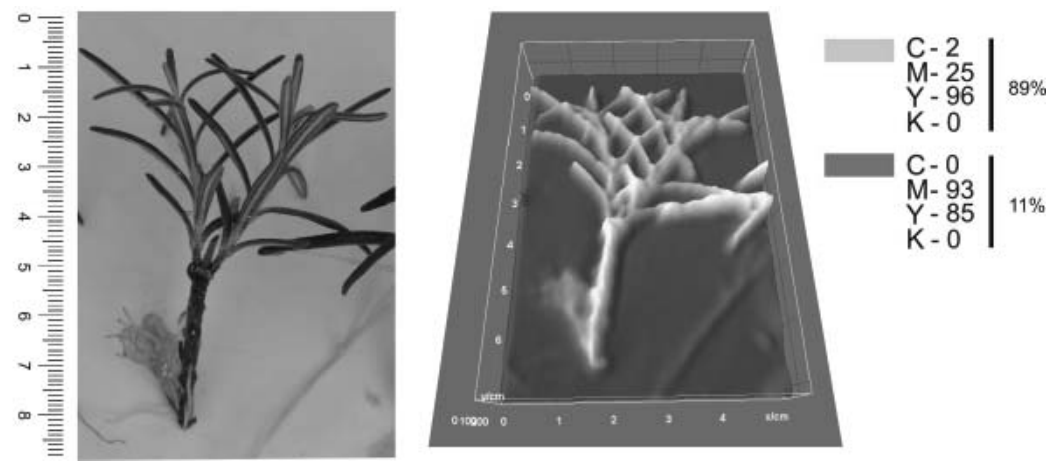

Fig. 10. Cutting development at Rosmarinus officinalis propagated on un-shaded water retaining starch polymers
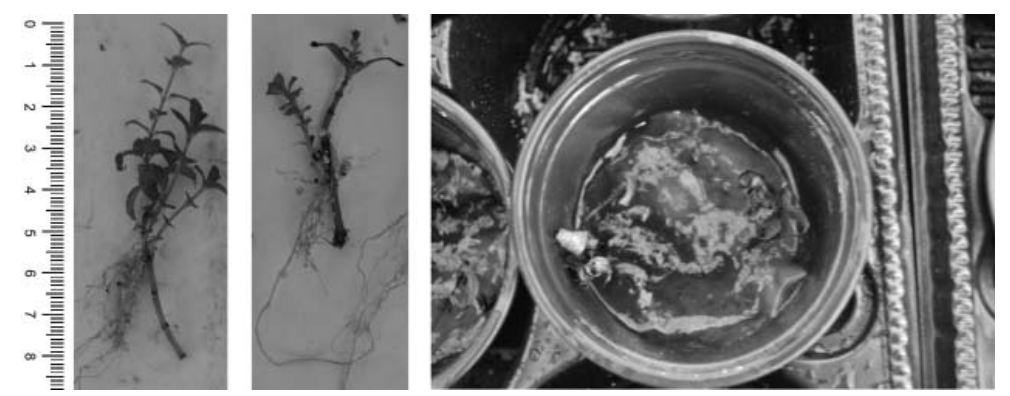

Fig. 11. Positive tropism at the rooting system of Mentha piperita propagated on water retaining starch polymers

All observed cuttings were introduced in a specific 3D software that transform simple raster images in 3D models with specific heat maps who revealed cutting development. Completed with the Pearson index, the 3D modeling image creates an accurate overview of the optimum propagation substratum (Fig. 9).

In case of Rosmarinus officinalis, Mentha piperita and Salvia officinalis propagation the 3D picture was divided in 2 CMYK colors with the following composition: C-2, M-25, Y-96, K-0 (color specific for the upper cutting development) and C-0, M-93, Y-85, K-0 (color specific for the lower cutting development).

The indicated above where analyzed by specific software, which generate percentage for each color.

For propagation on water retaining starch polymers, secondary roots suffered from water excess and lack of oxygen, creating roots prior 
to the collar with an positive tropism seeking for oxygen (Fig. 10).

Un-shaded water retaining starch polymers developed algae inside the substratum due to their perfect light absorption. This technological aspect was reduced at the shaded water retaining starch polymers, with a delayed development of algae (Fig 11).

The color diagram showed secondary root development for Rosmarinus officinalis on the studied substrates revealing abnormal positive tropism for the rooting system.

Salvia officinalis has the largest leaf area, susceptible for an increased value of evapotranspiration reacted well at the shading material obtaining a $61 \%$ rooting percent shaded perlite substratum, and $39 \%$ for the water retaining starch polymers substratum.

\section{CONCLUSION}

From the biological material point of view, Rosmarinus officinalis obtained the highest rooting percent $84 \%$ with a direct and positive correlation between cutting height and number of secondary roots.

Un-shaded perlite substratum reacted positive for cutting propagation at Rosmarinus officinalis and Mentha piperita. Salvia officinalis reacted positive for the shaded perlite substratum due to its large leaf area, and evapotranspiration rate.

For propagation on water retaining starch polymers, secondary roots suffered from water excess and lack of oxygen, creating roots prior to the collar with an positive tropism seeking for oxygen.

Water retaining starch polymers must be used as propagation substratum only as constitutive element besides another compound. This conclusion opens new frontiers for further research studies.
Acknowledgments. This paper was published under the frame of European Social Fund, Human Resources Development Operational Programme 2007-2013, projectno. POSDRU/159/1.5/S/132765.

\section{REFERENCES}

1. Andrade LB, Echeverrigaray S, Fracaro F, Pauletti GF, Rota L, (1999). The effect of growth regulators on shoot propagation and rooting of common lavender (Lavandula vera DC), Plant Cell, Tissue and Organ Culture 56:79-83.

2. Buschermohle Michael J, Grandle George F, (2004). Controlling the environment in greenhouses used for tomato production, Agricultural Extension Service, The University of Tennessee:1-10.

3. D'Antuono LF and Elementi S, (2006). Facts and Perspectives of Edible Lamiaceae: Flavour and Health, Industrial Exploitation, and the Consumer, Proc. It IC on Labiatae, Acta Hort. 723:33-50.

4. Fornes F, Mendoza-Hernandez D and Belda RM, (2013). Compost versus vermicompost as substrate constituents for rooting shrub cuttings, Spanish Journal of Agricultural Research 11(2):518-528.

5. Harknes R and Bratman S, (2000). Drug-Herb-Vitamin Interactions Bible. Prima Publ. Co. 430 p.

6. Joosen Ronny VL, Kodde Jan, Willems Leo AJ, Ligterink Wilco, Linus HW van der Plas and Hilhorst Henk WM, (2009). GERMINATOR: a software package for highthroughput scoring and curve fitting of Arabidopsis seed germination, The Plant Journal:3-11.

7. Lange Dagmar, (2004). Medicinal and Aromatic Plants: Trade, Production, and Management of Botanical Resources, Acta Hort. 629:177-197.

8. Nimet Kara, Baydar Hasan, (2013). Effects of Different Explant Sources on Micropropagation in Lavender (Lavandula sp.), Journal of Essential Oil Bearing Plants:250-255.

9. Pistelli L, Noccioli C, D'Angiolillo F and Pistelli L (2013). Composition of volatile in micropropagated and field grown aromatic plants from Tuscany Islands, Acta Biochimica Polonica:43-50.

10. Thomas SC Li (2004). Medicinal Plants - East Meets West, Proc. XXVI IHC - Future for Medicinal and Aromatic Plants, Acta Hort. 629:49-53. 